\title{
Creativity and innovation through design practice
}

\begin{abstract}
This paper reports on the author's work of evaluating the creative fostering techniques while engaging in collaborative cross-cultural design project with design practitioners and design educators. In a global educational environment that is filled with uncertainties and complex difficulties, how can instructors create and foster a learning situation that advances inventive, creative and critical thinking skills in students? What sort of methods and classroom atmospheres do educators need to elevate to face a testing electronic world, and in what capacity may students respond to such productive classroom situations?
\end{abstract}

Can creativity be fostered? And if so how will it impact the way design education is being delivered in Higher Educational institutes. This paper will reveal how by engaging in collaborative designing creativity can be fostered. By combining $\mathrm{C}-\mathrm{K}$ theory and other creative models to create and develop a method that ensures creative output results. This is presented in the final artefact of an authored book.

The analysis of the design project and observation of participants in the research reveals new methods and techniques, which is presented to the reader. These views place the reader in the context of the research project and assert a mix of certainty regarding the position of fostering creativity in design education.

This paper argues that creativity in the design process is based on several key factors, and Higher Educational Design Institutions needs to get on board with the evolving discussion in this area. It is therefore imperative that design educators are constantly engaged in design practice with industry practitioners to ensure that design knowledge and design practice is current and evolving.
Volume 5 Issue 4 - 2019

\section{Dilip Kumar Mothiram}

Assistant Professor, Director of Studies Fashion, School of

Textiles \& Design, Heriot-Watt University, UAE

Correspondence: Dilip Kumar Mothiram, MA, Assistant Professor, Director of Studies Fashion, School of Textiles \& Design, Heriot-Watt University Dubai Campus, DIAC UG 05, P O Box 294345, Dubai, UAE, Tel +97। 44358757 , Fax +97। 4 447 7350,Email D.K.Mothiram@hw.ac.uk

Received: June 20, 2019 | Published: July 15, 2019

\section{Introduction}

Creativity is the fuel that drives us forward. This statement truly defines 'design education' and cannot be more appropriate to my topic of research. However, within design education, educators like myself and others before me have struggled with the concept of fostering or instilling creativity in our students. We have all heard the phrase at one time or another that, "people are born with creativity", implying that this is not a skill that can be taught or something that can be learnt. So, the question arises that if you are not born with this 'creativity', and you wish to become a designer, how do you compete with those that have been lucky enough to receive these gifts naturally?

In my current position as a Higher Education lecturer in Fashion Design, I am in charge of the improvement, outline and conveyance of 'design' and 'production' courses. This involves research into new techniques for generation and plan through experimentation and expert practice, that intern illuminates and enhances design and production teaching methods. Through my practice of designing and investigation, I now understand the requirement for an impetus amid the 'design process' keeping in mind the end goal to improve 'creativity', which can be accomplished through 'collaborative designing' and the mixture of social and cultural diversity. Albeit numerous areas of 'design' education need improving, my range of interest and focal point is in design and production.

As a design educator, I have come across many students that struggle tremendously with visualising design ideas and design concepts. As their guide into the design world, I have many methods of conveying this knowledge but have fallen short in the area of creativity. Discussions with colleagues over the years have leaded me to the conclusion that creativity is something that can be fostered, if the individual is open to new ideas and concepts.

According to Csikszentmihalyi, ${ }^{1}$ 'Creativity is perceived as a social construct. Within the concept of social creativity, it is to move beyond the traditional conception of individual creativity. Creativity is discussed as a collaborative effort manifested in a real-world environment rather than some exceptional individual trait. Much human creativity arises from activities that take place in a social context in which interaction with other people and the artefacts that embody group knowledge are important contributors to the process.'

Based on the above I have created my 'design' research project, which includes many creative individuals collaborating on a single project with many different types of artefacts and outcomes. My involved participation and analysis of the design process is what will allow me to create a supporting guide for design professionals and students on how to foster, enhance and revive creativity, which will be presented in the form of a book.

The main aim of this research is to examine the ideas and concepts of creativity in design practise in order to use it to inform the development of creative pedagogy in design education. The project is field based and it unites experienced design professionals and novice designers from different design disciplines to work on a collaborative project. This project is driven and directed by a "Design Brief" which outlines the requirements and deadlines of the project. I will be fulfilling four different roles in the project, which will be as project leader, facilitator, designer and researcher, and all of these roles require my keen professional observational skills and experience. 
In order to examine the practice of creativity and innovation, several key elements had to be put into place:

a. First and foremost, participants were selected for their creative ability and this was assessed by examining their portfolio of work they produced previously and answering the online survey.

b. Participants were carefully selected for their creative abilities in design. Another important aim of the project was global collaboration, participants were also chosen to a certain extent based on their geographic location as well.

Design institutions worldwide utilise studio-based teaching or live projects to facilitate students' learning in a discovery-led way. This project builds on the above model by examining the learning and discovery that will take place from the collaborative design-based project.

The principal research question and title of the project, in this inquiry seeks to answer: How will fostering creativity and innovation through design practice with 'cross-cultural fusion' evolve existing pedagogy in design education?

A list of supplementary questions was also developed:

i. Can creativity in design education be facilitated?

ii. Can collaborative designing improve creativity?

iii. How will technology influence this process?

iv. Can design education evolve with industry practice?

v. Will this model be able to be applied to other design disciplines?

vi. How will design educators and design practitioners find creative balance and understanding?

vii. How will the inspiration of cross-culture impact this study?

viii. How can creative intervention create positive impact for designing?

ix. How can this research be disseminated via publication?

My project had the following objectives based on my research questions:

a) Discover new Research methodologies in Art and Design (A\&D)

b) Discover new pedagogical approaches to product creation in Fashion

c) Design a Curriculum structure of a Masters Programme in A\&D disciplines

d) Basic outline of a book: 'Cross-Cultural Fusion: A Design Research Project'

\section{Literature review}

This chapter will provide a synthesis of the current research related to the concept of creativity within education. The review of literature will begin by defining creativity in order for the reader to better understand creativity.

In order to research the concept of creativity, one must first seek to understand the definition of creativity itself. Scholars vary in their definitions of creativity, as the concept is difficult to reduce to any one specific circumstance. Whitman state, "Creativity, occurring across a diversity of domains such as art, literature, science, mathematics, and so on, is undoubtedly influenced by a wide range of psychological and social factors, making it difficult to define in a universally acceptable manner" (2010:109). Put simply, "Creativity, as has been established, is difficult to define" (Donnelly, 2004:161).

However, even though choosing one specific definition for creativity is difficult, it is still important to seek to understand creativity. One of the best ways to do so is to look at the work of multiple scholars and use their thoughts to combine one general definition. In doing so, one can better comprehend the concept of creativity, and thus conduct research related to creativity with greater validity.

According to Galbraith and Jones, "Creativity seems to be concerned with innovation, change, reflection, tolerance, challenge, and nurturing of the unforeseen to make something a reality" (p. 19). Teo and Waugh add to this definition, stating, "Some researchers have described creativity as the skill of bringing about something new and valuable" (p. 208). They go on to identify that "a creative result is both original and appropriate" (Teo \& Waugh, 2010:208).

A study conducted by Kampylis et al. ${ }^{2}$ found that "the majority of prospective teachers $(61.3 \%)$ shared the optimistic view that school is the best environment for students to manifest their creativity" (p. 23). Teo and Waugh add, "fostering creativity in students is considered to be important and, in some places, is considered to be a part of lecturer and teacher training" (p. 208).

Numerous scholars agree with this concept, that creativity is essential for both staying current with society as well as influencing it. "In order to keep up, more innovation is needed and more creativity is exhorted" (Craft \& Jeffrey, 2008:578).

While there are many benefits of incorporating creativity in higher education environments, one of the biggest reasons for doing so is the ability of creativity to equip its user for future successes. Gibson states, "It seems clear that if we, in higher education institutions hope to produce individuals who will succeed in our complex and rapidly changing world, the focus must remain firmly on creativity as an essential capacity".

Defining creativity can be a daunting task. It is a complex and multi-faceted concept. For the purpose of this study, creativity will be defined as intentional thought that is imaginative, inventive, original and/or contrary to the ordinary, resulting in action that promotes new ways of thinking.

The fostering of creativity is 'best achieved through a process-based or activity-based curriculum that engages students in challenging, novel and unpredictable ways of working and learning' (Jackson 2003, cited in Jackson 2006:213). ${ }^{3}$ Due to the rapidly evolving academic landscape a number of schools are 'rethinking their long-standing philosophies of design education' and due to 'heightened demands placed on designers are affecting the modes in which design education is delivered' ${ }^{4}$

Fashion training simply like the design business is developing at an exceptional rate, on the grounds that the world of design is evolving. For instance, numerous design graduates regardless of where they are based may work for a multinational organization that delivers products and designs for the worldwide commercial centre. A designer could be Italian, living in Dubai and planning for the Asian commercial centre. This can only happen if there is social and cultural understanding and collaborative working. 
The role of imagination in the creative process is essential in developing the capacities to observe and visualise in Higher Education Study, in the identifying and solving of problems, and in the making of critical and reflective judgements'. ${ }^{4}$ This subject benchmark from the QAA, and this is why I am focusing my research on 'creativity' because this is where I see the educational experience of designer lacking. The further lack of understanding of the changing global market place is why I have decided to use 'Cross-culture' as the research inspiration.

There is a shift from 'rudimentary skills in a specific design area towards a design pedagogy that values the core qualities inherent in the design process: the ability to collaborate and communicate, a capacity for empathy, an ability to articulate design insights to those in other fields, and the capability to act strategically' (Wolff \& Rhee, 2009, cited in Faerm, 2012:213). My project intends to develop creative strategies for designers, through design practice.

'Learning in art and design develops both an aesthetic sensibility and the capacity to be creative. The material outcomes of engagement with these characteristics are equally varied in art and in design, but both require the development of particular cognitive attributes. The role of imagination in the creative process is essential in developing the capacities to observe and visualise, in the identifying and solving of problems, and in the making of critical and reflective judgements'. This subject benchmark from the QAA, and this is why I am focusing my research on 'creativity' because this is where I see the educational experience of designer lacking. The further lack of understanding of the changing global market place is why I have decided to use 'Crossculture' as the research inspiration.

Cross-culture in this project will mean researching two distinct cultures, which has been chosen because of my extensive knowledge of working, teaching and living there. Chinese and Arabic cultures have also fascinated foreigners, because they have been closed to the world for so long. Arab culture refers to the culture in the countries in which the official language is Arabic. The Arab Culture is divided into three main parts, the Urban Culture (Al-Mudun), the Rural Culture (Ar-Reef), and the Nomad Culture (Al-Badow). Typically, most of the Gulf countries along with parts of Jordan and Iraq are considered Badow (Bedouins). Other countries' countryside such as Palestine, Syria, Lebanon, Algeria and Tunisia are considered Rural Cultures. Their cities are considered to be Urban Cultures. Chinese culture is one of the world's oldest cultures. The area in which the culture is dominant covers a large geographical region in eastern Asia with customs and traditions varying greatly between provinces, cities, and even towns as well. Important components of Chinese culture include ceramics, architecture, music, literature, martial arts, visual arts cuisine and religion. Traditional Chinese Culture covers large geographical territories, where each region is usually divided into distinct sub-cultures. Now, because of relaxed laws and the global workplace, exploration is possible and enjoyable. An apt definition by $\operatorname{Kim}(2001: 3)$ "In the dizzying interface of national, cultural, linguistic, and religious traditions, the once clear definition of 'us' and 'them' are being blurred. We are challenged to face one another's numerous cultural differences and search for profound human similarities".

\section{Project activity}

\section{Introduction}

The World Wide Web has become the global city, 'unhindered by distances and borders, with much more knowledge and possibilities to connect. Each person can connect to any other person relatively easily', as described by Boon (2014:121). ${ }^{6}$ What made this idea of the global city unique is that we can actively follow, share and discuss knowledge in a very direct manner. This concept very much appealed to my senses as designer, educated two and half decades earlier when this kind of technology and advantage did not exist.

Through my practice of designing and exploration, I have come to realize the need for a catalyst during the 'design process' in order to enhance 'creativity', which can be achieved through 'collaborative designing' and the infusion of cultural diversity. Although many areas of 'design' education need a revamping, my area of interest and focus is in design and production. I have examined the ideas and concepts of Creativity in Design Practice in order to use it to inform the development of creative pedagogy in design education. The main vehicle and source for my research was a Design Project.

The design project's Cross-cultural theme, which has been chosen because of my extensive knowledge of working, teaching and living in those regions. Chinese and Arabic cultures have also fascinated foreigners, because they have been closed to the world for so long. Now, because of relaxed laws and the global workplace, exploration is possible and enjoyable.

Participants were provided with a Design Brief an original artwork for inspiration and a partner to begin working on the project. Each team were provided with a different artwork so that the design results would defer, but all artwork was created with the same theme.

Participant had to work together to design and create and original product.

\section{Findings}

\section{Research question I: Can creativity in design education be facilitated?}

One of the real hindrances confronting educators wishing to consolidate imaginative methodologies in their teaching and learning has been the absence of rational rules and a pathway to guide them in making the obliged movement from out-dated instructing ways to deal with more creative methodologies. To change this prevailing culture, argues Jackson, ${ }^{3}$ we need to change our approach from penalising mistakes to one of appreciating that making 'mistakes' provides important lessons for learning. 'By perceiving 'mistakes' as opportunities for, and proof of, learning instead of failure, we begin to change the paradigm to one that is more enabling and valuing of creative effort' (Jackson 2006:197). ${ }^{3}$

Edwards ${ }^{7}$ suggests that the term 'creativity' has a vague nature; a gift that is only possessed by an exceptional few. However, research has drawn attention to the importance of fostering the creativity of all learners. ${ }^{8} 9$

Fostering creativity is "best achieved through a process-based or activity-based curriculum that engages students in challenging, novel and unpredictable ways of working and learning" (Jackson 2003 cited in Jackson 2006: 213). ${ }^{3}$

Participants viewed experiential learning and self-exploration as tied to creativity. Several participants indicated that creativity and creative thinking skills were tied to being able to think about the world outside of the classroom, about the repercussions of the actions 
people make, and learning to apply learning to real-world problems and events.

\section{Research question 2: What specific strategies were used in this study in order to foster creative behaviours?}

Strategies that were used to foster creativity in this project were based on the perceptions and ideas of the researcher regarding the nature of creativity and the characteristics he believes that a creative individual should demonstrate. The following strategies were identified as themes through the analysis of interview transcripts and field notes: differentiated instruction, regulation of the emotional climate, collaboration, and exploration.

Differentiated instruction: Differentiating is the procedure of changing or adjusting educational modules in a manner to match content, methodology and product in view of participants' differences in interests, learning, and adapting needs.

By differentiating the instructional techniques most participants felt that were given the opportunity to be themselves and to come up with new and interesting ideas. Differentiation and the participants' willingness to adapt to the expectations of the design project also supported another major theme of the emotional climate and the attempts at fostering trust, safety and confidence.

Emotional climate: Eventually amid the observations and interviews, most participants addresses the strategies they use to create a protected, trusting, and warm environment where colleagues and students felt that their thoughts would not be judged contrarily, and they would not be shunned from group work or activities.

\section{Conclusion}

This study provides a broad overview of the perceptions design educators and design practitioners hold towards creativity, the strategies educators use to foster creative thinking and behaviour in their students, and the strategies design practitioners use when working with design assistants and the environmental challenges and opportunities they navigate along the way. A mixed-methods approach was used to examine and investigate creativity fostering behaviours in participants. In Andiliou and Murphy's ${ }^{10}$ review and synthesis of educator's conceptualizations of creativity, only three studies out of the 17 they examined used a methodology, which made use of questionnaires, interviews and observations. Twelve used only questionnaires to measure teachers' beliefs and behaviours, while the remaining two used only interviews. The present study is significant in part because survey data is presented along with interview and observation data, thereby describing a more comprehensive view of the situation and demonstrating with greater precision the dynamic and reciprocal nature of the learning environment inhabited by educators and practitioners.

Several of the responses from the survey results were intriguing. The majority participants demonstrated positive feelings towards the concept of creativity itself. This is evidenced by the way participants engaged in the design project and also by indicating that everyone could grow in their creativity, but also that most participants identified creativity as a crucial component of designing and living successfully.

The current structures in higher education were identified as another significant barrier to creativity's implementation. These structures included the lack of time afforded to faculty members to complete job requirements, along with significant workloads that contributed to that lack of time. Educator participants identified that the current class sizes and physical environments also operated as barriers to creativity.

Among the listed structures in higher education that hindered creativity were also evaluation processes for faculty members, along with the current systems of assessment for classroom learning. And finally, content requirements were also listed as a structure that afforded little Creativity.

Based on the results of this study, along with the implications listed above, it is important to note two things. First, DBR research conducted should lead to an increased awareness and identification of new design theories and design practice. This paper has outlined the current status of design participants' perceptions of creativity within a design project. It will now address several ideas for identifying what should be done regarding creativity in higher education, along with ways in which both institutions/educators and design practitioners can obtain those goals.

Secondly, there is a significant need for more research regarding creativity in design education. It is important for the reader to note that the concepts listed for research are not exhaustive.

\section{Acknowledgments}

None.

\section{Conflicts of interest}

The authors declare that they have no competing interests.

\section{References}

1. Csikszentmihalyi M. Creativity: flow and the psychology of discovery and invention. New York: Harper Collins; 1996.

2. Kampylis P, Berki E, Saariluoma P. In-service and prospective teachers conceptions of creativity. Thinking Skills and Creativity. 2009;4(1):15-29.

3. Jackson N. Imagining a different world. In: Oliver M, Shaw M, Wisdom J, editors. Developing Creativity in Higher Education: An Imaginative Curriculum. London, New York: Routledge; 2006:1-9.

4. Faerm S. Towards a future pedagogy: the evolution of fashion design education. International Journal of Humanities and Social Science. 2012;2(23):210-219.

5. QAA. Subject benchmark statement art and design. 2008.

6. Boon W. Defining Creativity. Amsterdam: BIS Publishers; 2014.

7. Edwards SM. The technology paradox: Efficiency versus creativity. Creativity Research Journal. 2000;13(2):221-228.

8. Csikszentmihalyi M. Intrinsic motivation and effective teaching: A flow analysis. New Directions for Teaching and Learning. 1982;10:15-26.

9. Mcwilliam E. Is creativity teachable? Conceptualising the creativity/ pedagogy relationship in higher education. 30th HERDSA Annual Conference: Enhancing higher education, theory and scholarship Proceedings, Adelaide: HERDSA; 2007.

10. Andiliou A, Murphy PK. Examining variations among researchers' and teachers' conceptualizations of creativity: A review and synthesis of contemporary research. Educational Research Review. 2010;5(3):201-219. 